\title{
PRESENTACIÓN
}

\section{PASIÓN Y OFICIO: BEATRICE WEBB EN LA FUNDACIÓN DE LA SOCIOLOGÍA}

\author{
Juan José Castillo \\ Universidad Complutense de Madrid \\ E-mail: jjcastillo@cps.ucm.es
}

El nombre de Beatrice Webb, ya sea sola o acompañada de su marido, Sidney, e incluso bajo su nombre de soltera, Beatrice Potter, no suele aparecer cuando se hace balance de nuestros clásicos, o se revisa nuestra herencia y patrimonio como sociólogos. Y, sin embargo, la historia e institucionalización de la sociología, e incluso más ampliamente de las ciencias políticas y de la economía, no sólo están vinculadas a su nombre, sino que hallarían difícil explicación sin ella ${ }^{1}$.

En el importante y decisivo momento para la orientación actual de las ciencias sociales en general, pero más específicamente de la Sociología del Trabajo, que fue lo que he llamado en otro lugar la «situación 1960»², el British Journal of Sociology dirá que, para 1898, fecha de la publicación de La democracia industrial por los Webb, y diez años después de la publicación del «Diario de una investigadora», se había asistido a la creación, a la fundación sobre sus bases empíricas y teóricas, de "una nueva sociología» ${ }^{3}$.

De hecho, Nathan Glazer, analizando en 1959 «la aparición de la investigación social en Europa», dedica una cuidada atención al trabajo de socióloga de Beatrice Webb, cuando aún se apellidaba Potter, y a su participación en la

\footnotetext{
Veáse L. MCDonald, «Classical social theory with the women founders included», 1995.

J. J. CASTILlo, Sociología del trabajo: un proyecto docente, 1996.

3 T. SimeY, 1961, p. 121.
} 
gran investigación, dirigida por Charles Booth, Vida y trabajo de los obreros de Londres, a la que he dedicado atención en un trabajo anterior ${ }^{4}$. Para Glazer, "el libro más importante para entender el despegar del enfoque científico social contemporáneo es Mi aprendizaje, de Beatrice Webb»5.

Esta autobiografía, basada en los diarios de Beatrice, es, como se sabe, un auténtico éxito literario, que continúa reimprimiéndose hoy en día. En ella podemos encontrar una de esas escasísimas joyas que permiten la reconstrucción de una vida y, sobre todo, para lo que aquí nos importa, de una experiencia iniciática, de la formación de una capacidad de analizar la sociedad, como le gusta tanto decir: creed and craft, pasión por la reforma social, y oficio de investigador que se adquiere con la reflexión teórica puesta a prueba con la investigación concreta, directa, no delegada ni mediada. "Beatrice Potter desarrolló gradualmente el sentimiento de que ella debía ver por sí misma cómo eran los objetos de su interés y compromiso", esto es, los trabajadores y trabajadoras ${ }^{6}$.

En $M i$ aprendizaje se recoge con detalle la formación y lecturas de Beatrice, la influencia tan próxima de Spencer en su primera formación, y su posterior ruptura con el individualismo spenceriano, junto con la presentación y reflexión sobre su propia aproximación a la realidad social, para comprenderla, entenderla y, eventualmente, transformarla.

"Páginas del diario de una chica trabajadora», como se llamó el texto que reproducimos a continuación en su edición original, es un momento especialmente fundante en su formación como socióloga, puesto que forma parte de un conjunto de prácticas de investigación que darán lugar a una serie de publicaciones sobre problemas y sectores conexos: los estibadores de Londres, el sector de la confección de prendas baratas, o la vida de la comunidad judía en Londres, paso absolutamente imprescindible para poder dar cuenta del sweeting system.

Este proceso de investigación, que forma parte de la investigación colectiva liderada por Charles Booth ${ }^{7}$, permitirá a Beatriz disponer de un censo de establecimientos fabriles, de análisis que hoy llamaríamos secundarios, sobre un conjunto de informaciones que son, sin duda, el mayor esfuerzo investigador sobre la pobreza en Londres (y en el mundo: el "modelo Booth" se extenderá especialmente en Estados Unidos), en el cambio del siglo XIX al XX.

${ }^{4}$ J. J. CASTillo, «En la jungla de lo social: Beatrice Webb, nuestra contemporánea», Actas de las II Jornadas de Historia Económica de las Relaciones Laborales, Sevilla, Escuela de Relaciones Laborales, 2001.

5 N. GLAZER, "The rise of social research in Europe», 1959, p. 58.

${ }^{6}$ N. Glazer, ibidem, p. 59. Y continúa, «eso llevó a Beatrice Potter y Charles Booth a una implicación directa con los seres humanos que estaban dentro del problema, y hacia el intento de basar cualquier afirmación general sobre los pobres y las clases trabajadoras, en vinculación directa con ellos».

${ }^{7}$ K. BALES, "Lives and labours in the emergence of organised social research, 1886-1907", 1999. 
Por ello, y puesto que esta pieza sociológica se presenta aquí aislada, conviene recordar que lo que la hará meritoria de su reproducción como clásico es precisamente su llamada de atención hacia el hecho de la interdependencia entre todas las fases de la investigación social. Así lo destacará Buford Junker en su clásico Field work, en 1961, incluyendo una reflexión más desarrollada, pero establecida ya en sus fundamentos por Beatrice por las fechas en que escribe este texto: debe ser la misma persona, sin división del trabajo, quien planifique, elabore y analice los resultados, si se quiere que las ciencias sociales desarrollen su capacidad de entendimiento de la realidad social ${ }^{8}$.

La autora recuerda, en la nota final de su artículo, el conjunto de textos que lo enmarcan, y cuyas referencias originales se incluyen en la bibliografía que acompaña a esta presentación. Si el espacio lo hubiera permitido, el artículo "Cómo acabar con el sweeting system», su intervención en junio de 1892 en el Congreso de las Sociedades Cooperativas, habría sido un buen contraste con el fragmento de "diario de campo" aquí presentado. Diario que pertenece más a la "cocina de la investigación", a la voluntad de mostrar las herramientas y las dificultades de un oficio que sólo se aprende, como todos, haciéndose.

Una reflexión de conjunto sobre la propia experiencia de investigación de los esposos Webb, que es a la vez una propuesta metodológica y epistemológica, es la recogida en su libro de 1932, Métodos de estudio social, cuya edición de 1975 lleva una espléndida introducción de T. H. Marshall. Pero, para ser consecuentes con su propia propuesta, lo que podríamos llamar «el enfoque de los Webb», o, como ellos dijeron en algún momento, "la especialidad de la casa Webb», conviene enviar al lector a los propios productos de investigación, a los libros y artículos publicados. A su obra en general, pero más específicamente a la publicada en esos diez primeros años que median entre el "Diario de una investigadora", 1888, y La democracia industrial, 1898.

De esta última se ha escrito ayer mismo, para subrayar su carácter de obra maestra, que "toda la historia del sindicalismo británico ha sido una nota a pie de página a los Webb»". Para remachar más adelante que "La democracia industrial es el libro más completo y original que se haya escrito jamás sobre los trabajadores ingleses. Su riqueza es tal que más de cien años después de su primera edición puede aún sugerir líneas frescas de investigación». Y, para sus autores, su método se ejemplifica investigando: en La democracia industrial "hay la misma insistencia - escriben en 1898 - en la unidad de los estudios sociales»; "su enfoque de conjunto se funda en la creencia de que la significación de las estructuras sociales sólo pueden ser comprendidas por una investi-

8 B. Junker, Fieldwork, 1961, pp. 205 y 163. Para una elaboración temprana de esta perspectiva, veáse el apéndice a My apprenticeship, edición 1938, pp. 464-469, «Personal observation and statistical enquiry", donde propone, "hand in hand», la "quantitative observation of aggregates» y la "qualitative observation of units».

9 Royden Harrrison, The life and times of Sidney and Beatrice Webb, 2000, p. 218. La siguiente cita en el texto en p. 236. 
gación directa, sistemática y laboriosa de su comportamiento real, tanto en el pasado como contemporáneo» ${ }^{10}$.

Beatrice Potter había dejado escrito en su diario el porqué de su primera "salida al campo», cuando en el verano de 1883 fue por primera vez a Bacup, en Lancashire. El "Diario...» aquí publicado es un momento intermedio en el camino hacia la reflexión que hace al hilo de una de sus obras maestras, La democracia industrial. Pero en esa trayectoria, a mi juicio, hay un hilo conductor, o si se quiere, como he escrito en otro lugar, un crisol, que no es otro que el trabajo de campo, el análisis teóricamente informado de la realidad social: "observar, día a día, en sus casas y en sus talleres, un número suficiente de familias de trabajadores manuales normales que me permitiera visualizar la clase como un todo»" ${ }^{11}$.

La obra de Beatrice Webb ha recibido un nuevo impulso en los últimos años con la edición crítica de sus diarios completos, y con estudios monográficos que nos devuelven la riqueza de una personalidad, junto a su marido, Sidney, que ha sido una pieza fundamental en la fundación y asentamiento mismo de la sociología en el siglo $\mathrm{XX}^{12}$. La modesta pretensión de esta nota, y la edición en castellano de una de sus piezas metodológicas más citadas y reeditadas, es llamar la atención de nuestra comunidad científica hacia la que es, sin duda alguna para mí, una de las "damas» fundadoras de nuestra disciplina tal y como hoy la practicamos. Leer, o releer, la obra de Beatrice Webb es, también, una buena propuesta para los sociólogos en formación: su ejemplo y su vida, su aprendizaje, puede ser una buena guía de perplejos en estos tiempos de incertidumbre.

Apenas transcurridas tres semanas desde la publicación del «Diario de una investigadora", el 5 de mayo de 1888, hizo esta anotación en su diario: "me encanta la vida de la gente en el East End; la realidad de sus esfuerzos y metas; la simplicidad de sus penas y alegrías; creo que puedo dar cuenta de ellas y dar cuenta del lado trágico al igual que del cómico. Hasta cierto punto puedo captar las fuerzas que mueven arriba y abajo, creciendo o hundiendo, a este amplio conjunto de seres humanos. El costosísimo estudio de detalle ayudará al conocimiento del todo, hacia lo cual estoy siempre avanzando. Dejaré escalones tallados en la roca, y desde su cima la humanidad podrá al fin dibujar la tierra conquistada de la vida social» ${ }^{13}$.

${ }^{10}$ Sidney y Beatrice WebB, Industrial Democracy, 1898, p. 281.

${ }_{11}$ Beatrice WebB, My aprenticeship, edición 1938, p. 175. Se refiere al verano de 1883. J. J. CASTILlO, "Un camino y cien senderos: el trabajo de campo como crisol de disciplinas», 2000.

12 Destaco aquí, especialmente, dos obras: la de NorD, The appprenticeship of Beatrice Webb, de 1985, de la que el capítulo 6, "Social investigation», es una magnífica presentación del texto que editamos. Especialmente, p. 174. Y la más reciente de HARRISON, 2000, ya citada. Sin duda, la más completa y "autorizada», pues es editada bajo los auspicios de la London School of Economics.

${ }^{13}$ Beatrice WebB, My apprenticeship, p. 320. La presentación de todos los preparativos para el trabajo de campo, su entrenamiento previo como pantalonera, y el conjunto de notas de trabajo, se recogen en la obra mencionada, pp. 311-344. 


\section{REFERENCIAS}

BALES, Kevin: «Lives and labours in the emergence of organised social research, 1886-1907», en Journal of Historical Sociology, vol. 9, núm. 2, junio 1996, pp. 113-138.

Bоотн, Charles: Life and labour of the people of London. Final volume: Notes on social influences and Conclusion, Londres, MacMillan, 1903, $451 \mathrm{pp}$.

CASTILlO, Juan José: Sociología del trabajo: un proyecto docente, Madrid, CIS-Siglo XXI, 1996, 208 p.

- "Un camino y cien senderos: el trabajo de campo como crisol de disciplinas", en Revista de Antropología Social, 2000, 9, pp. 51-74.

Cole, Margaret: "The Webbs and Social Theory», en The British Journal of Sociology, vol. XII, núm. 2, junio 1961, pp. 93-105.

GlaZER, Nathan: "The rise of social research in Europe», en Daniel Lerner (ed.), The human meaning of the social sciences, Cleveland y Nueva York, The World Publication Company, 1959, pp. 43-70.

Harrison, Royden J.: The life and times of Sidney and Beatrice Webb. 1858-1905: the formative years, Londres, Macmillan, 2000, 397 pp.

JUNKER, Buford: Field work. An introduction to the social sciences, Chicago, The University of Chicago Press, 1960 [Second impression, 1962], 208 pp.

MCDonaLD, Lynn: «Classical social theory with the women founders included», consultado como paper, 1995; ahora incluido en Charles CAMIC, Reclaiming sociological classics, Oxford, Blackwell, 1997.

NORD, Deborah Epstein: The apprenticeship of Beatrice Webb, Londres, Macmillan, 1985, 285 pp.

PALMER, Vivien M.: Field studies in sociology. A students manual, Chicago, The University of Chicago Press, 1928 [Second impression, 1929], 281 pp.

POTTER, Beatrice: "The docks», en Ch. Воотн, Life and labour of the people of London. First Series: Poverty (4), Londres, MacMillan, 1902 [publicación original, 1889], pp. 12-36 [reimpreso con autorización del editor de Nineteenth Century, septiembre 1887].

- "The tailoring trade», en Ch. Воотн, Life and labour of the people of London. First Series: Poverty (4), Londres, MacMillan, 1902 [publicación original, 1889], pp. 37-68 [reimpreso con autorización del editor de Nineteenth Century, agosto 1888].

- "The jewish community», en Ch. Bоотн, Life and labour of the people of London. First Series: Poverty (3), Londres, MacMillan, 1902 [publicación original, 1889], pp. 166-192.

- The cooperative movement in Great Britain, Londres, Gower, 1891.

SimeY, T. S.: "The contribution of Sidney and Beatrice Webb to Sociology», en The British Journal of Sociology, vol. XII, núm. 2, junio 1961, pp. 106-123.

WALLERSTEIN, Immanuel (ed.): "The heritage of sociology and the future of the social sciences in the 21 st. century», monográfico de la revista Current Sociology, vol. 46, núm. 2, abril 1998, 144 pp.

WebB, Beatrice: My apprenticeship, with an introduction by Norman MacKenzie, Cambridge, [etc.], Cambridge University Press-London School of Economics, 1979,i-xxxix+429 pp. [edición original, 1926].

- My apprenticeship, Harmondsworth, Penguin-Pelican, 1938, 2 vols., 503 pp.

- The Diary of Beatrice Webb. Volume one, 1872-1892: Glitter around and darkness within, Londres, Virago in Association with The London School of Economics and Political Science, 1982, 386 p. [Edited by Norman and Jeanne MacKenzie].

Webb, Sidney y Beatrice: Historia del sindicalismo, 1666-1920, Madrid, Ministerio de Trabajo, 1990, 775 pp. [edición original, 1894; esta edición reproduce la de 1920].

- Industrial Democracy, Nueva York, Augustus M. Kelley Reprints, 1965, 929 pp. [edición original, Londres, 1898; esta edición reproduce la de 1920, con los prólogos de la edición de 1902 y 1920].

- Problems of modern industry, Londres, Longmans, Green and Co., 1898, 286 pp.

- Methods of social study, Londres, London School of Economics and Political Science-Cambridge University Press, 1975 [edición original, 1932], 263 pp. [With an introduction by T. H. Marshall]. 